\section{Military Technical College Kobry El-Kobbah, Cairo, Egypt.}

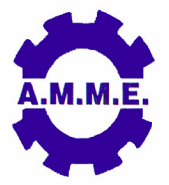

\title{
AN EXPERIMENTAL AND NUMERICAL STUDY OF SUBMERSIBLE PRESSURE HULL
}

\author{
M. Moustafa*, E. E. El-Soaly ${ }^{* *}$ and A. Badawy
}

\begin{abstract}
The analysis of pressure hull is of great importance among structural engineering due to the complexity involved in the collapse mechanism of stiffened shell structures. Due to this complexity, only a limited amount of test data was available to evaluate the effect of the external pressure on the stability of stiffened shell structure. The proposed work considers theoretical study and experimental test data of the pressure hull. Uniformly ring stiffened cylinder, dome and conical elements of a pressure hull are considered. For the same experimentally considered model, a numerical study using Finite Element Method (by ABACUS program) is also presented. The obtained experimental and numerical results are compared.
\end{abstract}

\section{KEY WORDS}

Pressure hulls, Ring stiffened shell, Finite element Method.

\footnotetext{
* Egyptian Armed Forces.

** $\quad 10^{\text {th }}$ of Ramadan High Institute of Technology.
} 


\section{NUMOCLATURE}

P Hydrostatic external pressure.

$\mathrm{R} \quad$ Shell radius.

h Shell thickness.

D Flexural rigidity.

E Modulus of elasticity.

$v \quad$ Poisson's ratio.

$\vartheta \quad$ Angle of rotation of tangent to the shell meridian.

$\mathrm{N} \quad$ Normal force per unit length.

Q Shear force per unit length.

M Bending moment per unit length.

$\sigma_{\max }$ Maximum normal stress.

w Radial deflection.

\section{INTRODUCTION}

Designing stiffened shells under external hydrostatic pressure is a complex task. Different buckling modes are often relevant, each one affected distinctly by the effects of mode interaction, boundary conditions, shape imperfections and residual stresses. General purpose Finite Element programs are now available which can, in principle, estimate knock-down factors taking into account all of these aspects. The models used, however, have to be validated in the light of mesh studies, other theories, numerical results and, experimental results. Even after such a painstaking process, the designer cannot expect to be truly representing the behavior of a real structure due to factors beyond his control, such as spatial variation of material properties and shape imperfections, degree of workmanship and maintenance. Structural design in general has been traditionally based on deterministic methods in which the above uncertainties are tackled, broadly speaking, by designing the structure to have some safety margin against the worst possible combination of these effects, sometimes regardless of how likely (or unlikely) such a combination may be.

Timoshenko and Gere [1] gave the classical solution of the buckling pressure for a very long cylindrical shell with uniform thickness under external hydrostatic pressure by considering that the cylinder is in plane strain and solving for the buckling load of a ring. The plane strain assumption that allows one to model shell collapse as ring collapse is valid when length-to-diameter ratio of the shell is greater than 25 . When the length-to-diameter ratio is less than 25 , the shell must be treated as one with finite length since the stiffening effect of the end constraints are no longer negligible and will affect the pressure at which buckling occurs. Xue, M.S. Hoo and Fatt [2] gave an exact solutions of elastic buckling pressure for a non-uniform, long cylindrical shell subjected to external hydrostatic pressure are derived. The Defense Research and Development Canada [3] indicated that the analysis of the experimental data suggests that the role of eccentricity due to one-sided shell thinning can have an equal or greater strength-reducing effect than the thinning itself. 
The present work has examined experimentally the behavior of ring-stiffened shell with externally hydrostatic pressure. The shells represent a similar structure of submarine. A finite element analysis for an identical geometry is also performed and discussed in the light of experimental results. Little information is available on the effects of scaling. Work in this field is vital particularly if the results of any experimental test are to be successfully correlated to full scale event.

In this paper, the stress analysis of a submersible pressure hull subjected to external hydrostatic pressure under initial hydrostatic pressure is investigated using classical thin shell theory. The effects of ring stiffeners are proposed over the surface of the shell, the stiffened shell can be modelled as an equivalent uniform orthotropic shell. The pressure hull is constructed from three parts: ring-stiffened cylindrical shell, cone and dome. The governing equations are described in this section.

\section{GOVERNING EQUATIONS}

\section{Membrane Stresses}

The membrane meridinal and hoop stresses $\sigma_{m}$ and $\sigma_{H}$ are [4] :

- In cylindrical shell

$$
\begin{aligned}
& \sigma_{m}=-\frac{p R}{2 h} \\
& \sigma_{H}=-\frac{p R}{h}
\end{aligned}
$$

- In spherical shell

$$
\begin{aligned}
& \sigma_{m}=-\frac{p R}{2 h} \\
& \sigma_{H}=-\frac{p R}{2 h}
\end{aligned}
$$

- In conical shell

$$
\begin{aligned}
& \sigma_{m}(x)=-\frac{p}{2 h} x \sec \alpha \tan \alpha \\
& \sigma_{H}=-\frac{p}{h} x \sec \alpha \tan \alpha
\end{aligned}
$$

Because of boundary effects at locations where the deflections are restricted, or there is a change in geometry, such as the cylindrical-to-spherical shell junction, the membrane theory is inadequate to maintain deflection and rotation compatibility between the shells. Therefore, it is very important to determine the bending stress and field displacement by using moment theory.

\section{Bending Stresses}

At the junctions between the cylindrical shell and both the spherical and conical shells, stiffening rings of T-shape cross-section are fixed. The stresses at the vicinity of these junctions are mainly bending stresses. A general differential equation in the form [5]: 


$$
\frac{d^{4} w}{d x^{4}}+4 \beta^{4} w=-p
$$

Where, the parameter $\beta$ for cylindrical, spherical and conical shells are given as:

$$
\beta_{c l}^{4}=\frac{3\left(1-v^{2}\right)}{R^{2} h^{2}} \quad \beta_{s}^{4}=\frac{3\left(1-v^{2}\right)}{\left(R^{2}-l^{2}\right) h^{2}}
$$

and $\quad \beta_{c}^{4}=\frac{3\left(1-v^{2}\right)}{(R-l \sin \alpha)^{2} h^{2}}$

where $\mathrm{I}=1.25 \pi / \beta$

the solution of the def. eqn.(7), within a narrow distance from stiffening ring, $x<1$ (figure 1), can be written in the form,[6]:

$$
w=e^{-\beta x}\left(c_{1} \sin \beta x+c_{2} \cos \beta x\right)+\frac{p}{4 \beta^{4} D}
$$

The constants $c_{1}$ and $c_{2}$ are chosen to make the displacement $w$ and the angle of rotation $\mathrm{dw} / \mathrm{dx}$ zero at the origin of $\mathrm{x}$ (at the stiffener of the junction between the cylinder and the hemisphere). We then obtain:

$$
c_{1}=c_{2}=-p / 4 \beta^{4} D
$$

and

$$
w=\left[1-e^{-\beta x}(\sin \beta x+\cos \beta x)\right] \frac{p R^{2}}{E h}
$$

where $\quad D=\frac{E h^{3}}{12\left(1-v^{2}\right)}$

The bending moment expressions are given as:

$$
M_{x}=\frac{p R h}{2 \sqrt{3\left(1-v^{2}\right)}} e^{-\beta x}(\cos \beta x-\sin \beta x)
$$

The bending moment in tangential direction $\mathrm{M}_{\mathrm{H}}$ is related to the meridional moment by [7]:

$$
\mathrm{M}_{\mathrm{H}}=v \mathrm{M}_{\mathrm{x}}
$$

The maximum normal stresses due to bending moments occur at inner and outer faces of the considered shell are:

$$
\left(\sigma_{\max }\right)_{x}= \pm \frac{6 M_{x}}{h^{2}}
$$


The total stress, at the outer and inner surfaces, can be obtained from superimposing of membrane stresses and bending stresses then:

$$
\sigma_{x}^{\max }=\frac{3 p R}{h \sqrt{3\left(1-v^{2}\right)}}
$$

And the stress-strain relations are:

$$
\begin{gathered}
\mathcal{E}_{x}=\frac{\sigma_{x}}{E}-v \frac{\sigma_{\theta}}{E} \\
\varepsilon_{\theta}=\frac{\sigma_{\theta}}{E}-v \frac{\sigma_{x}}{E}
\end{gathered}
$$

\section{PLASTIC DEFORMATION IN PLATES}

The deferential equation of equilibrium of a rectangular plate, fig. 1, under uniform load is given in the form [8]:

$$
\nabla^{2} w=\frac{-p}{D}
$$

Consider a plate clamped at its four ends which super loaded such that two opposite ends are totally plastic $(x=0, x=a)$ and the other two ends $(y=0, y=b)$ are partially plastic as shown in fig. 2 . When the load is released, the plate does not return to the original shape, and the plate undergoes to known ultimate plastic moment $M_{\cup}$ at $x=0$, $x=\mathrm{a}$ and to undetermined moment $\mathrm{M}_{\mathrm{y}}$ at ends $y=0, y=\mathrm{b}$, depending on the depth of plastic region throw the plate thickness. Due to the formation of plastic hinges at the plate contour, the boundary conditions can be considered as:

At $x=0, x=a=240 \mathrm{~mm}: w=0, M_{u}=M_{x}$ and at $y=0, y=b=90 \mathrm{~mm} ; w=0, M_{y}$ is unknown.

In this case, where the load is released, the right hand side of equilibrium equation is zero, and the equilibrium equation reaches the form:

$$
\nabla^{2} w=0
$$

A possible solution of the above equation is expressed as:

$$
\nabla^{2} w=0 \quad \text { or } \quad \frac{d^{2} w}{d x^{2}}+\frac{d^{2} w}{d y^{2}}=0
$$

The last equation can be separated to be in form:

$$
\frac{d^{2} w}{d x^{2}}=\frac{d^{2} w}{d y^{2}}=k
$$

Two separate differential equations are obtained in terms of variables $x$ and $y$ 


$$
\frac{d^{2} w}{d x^{2}}=k \quad \text { and } \quad \frac{d^{2} w}{d y^{2}}=-k
$$

Solutions of these two differential equations are:

$$
w=\frac{1}{2} k x^{2}+x f_{1}(y)+f_{2}(y)
$$

and

$$
w=-\frac{1}{2} k y^{2}+y f_{1}(x)+f_{2}(x)
$$

Satisfying boundary conditions along sides $x=0$, and $x=\mathrm{a} \rightarrow w=0$ then,

$$
f_{2}(y)=0 \quad \text { and } \quad-\frac{1}{2} k a=f_{1}(y)
$$

Hence the deflection $w$ can be expressed in the following parabolic form:

$$
w=\frac{k}{2}\left(x^{2}-a x\right)
$$

In a similar way satisfaction of boundary condition along sides $\mathrm{y}=0, \mathrm{y}=\mathrm{b} \rightarrow w=0$ we get:

$$
w=\frac{k}{2}\left(y^{2}-b y\right)
$$

The bending moment expressions in a general case are:

$$
\begin{aligned}
& M_{x}=D\left(\frac{d^{2} w}{d x^{2}}+v \frac{d^{2} w}{d y^{2}}\right) \\
& M_{y}=D\left(\frac{d^{2} w}{d y^{2}}+v \frac{d^{2} w}{d x^{2}}\right)
\end{aligned}
$$

Substituting the expression of $w$, in terms of $x$ into the above equation of $M_{x}$ leads to:

$$
\begin{aligned}
& M_{x}=\frac{32 D w^{*}}{a^{2} b^{2}}\left[\left(y^{2}-b y\right)+v\left(x^{2}-a x\right)\right] \\
& M_{y}=\frac{32 D w^{*}}{a^{2} b^{2}}\left[\left(x^{2}-a x\right)+v\left(y^{2}-b y\right)\right]
\end{aligned}
$$

At $x=0$ and $x=a$,

$$
M_{x}=\frac{4 M_{u l t}\left(y^{2}-b y\right)}{b^{2}}
$$


and

where,

$$
w^{*}=\frac{a^{2}}{8 D} M_{u l t}
$$

$M_{u l t}=\frac{1}{4} \sigma_{y} h^{2}$

$\sigma_{y} \ldots$ is the yield stress of the material.

Considering equations 18 and 19 the radial deflection w may be expressed as:

$$
w=w^{*}\left[16 \frac{\left(x^{2}-a x\right)\left(y^{2}-b y\right)}{a^{2} b^{2}}\right]
$$

where,

$\mathrm{W}^{*}$ is the maximum value of radial deflection at $\mathrm{w}(\mathrm{a} / 2, \mathrm{~b} / 2)$.

$$
w^{*}=\frac{3 a^{2}\left(1-v^{2}\right)}{2 E h} \sigma_{y}
$$

and

$$
\mathrm{D}=\mathrm{Eh}^{3} / 12\left(1-v^{2}\right)
$$

\section{EXPERIMENTAL WORK}

A substantial amount of work has been performed so far to analyze stress distribution throughout stiffened cylindrical shell. Experiments are carried out on a model with the same dimension as the numerical analysis as shown in fig. 3 and fig.4. Several points are measured as shown in fig. 5 using strain gauges [9].

Pressure is raised in the pressure tank until reaching eighteen bars then a sudden drop in pressure occurred. Plastic deformations are noticed and as well as a separation between the two flange (cylinder \& hemisphere) occurred as shown in fig. 6 and fig. 7. Consequently, pressure drops inside the cylinder.

\section{NUMERICAL ANALYSIS VERIFICATION}

A substantial amount of work has been performed so far to investigate the analysis of ring stiffened shell. The geometrical configuration, boundary condition, material property and element mesh are described in this section. The model consists of a stiffened cylindrical shell with $250 \mathrm{~mm}$ diameter having three T-shape W10x20 mm stiffeners and connected by each end with hemispherical shell $(\Phi=250 \mathrm{~mm})$ and conical shell $(250 \mathrm{~mm}$ long) respectively. The boundary condition and load description are shown in fig. 8. The model has constructed from DIN 1623-2 steel with: $\mathrm{E}=209 \mathrm{GPa}, v=0.289, \rho=7800 \mathrm{~kg} / \mathrm{m}^{3}, \sigma_{Y}=380 \mathrm{MPa}$ and $\sigma_{\mathrm{ult}}=468 \mathrm{MPa}$.

A finite element model is built using Abacus software [10] dividing the pressure hull into three sections and then these results in fig. 9 are compared to theoretical ones. Several numerical approaches have been proposed and validated through experimental testing. 


\section{RESULTS AND CONCLUSIONS}

Another test can be added to the limited amount of test data to evaluate the effect of external pressure on stiffened shell. The results of the test are compared with the theoretical and numerical results. Table 1 shows the comparison between the plastic deformations happened in the deformed part of the cylinder shell due to experimental test fig. 10 and the theoretical calculations by equation 26 .

Table 1. Radial Deflections Comparison.

\begin{tabular}{|l|c|c|c|c|c|c|c|c|c|c|}
\hline Location (points) & 1 & 2 & 3 & 4 & 5 & 6 & 7 & 8 & 9 \\
\hline $\mathrm{W}(\mathrm{cm})$ & theoretical & 3.17 & 4.13 & 4.72 & 4.13 & 2.6 & 3.2 & 4.19 & 4.19 & 1.8 \\
\cline { 2 - 10 } & experimental & 2.2 & 2.8 & 3.5 & 2.8 & 1.5 & 0.8 & 1.7 & 1.5 & 0.8 \\
\hline
\end{tabular}

Another approaching between the strain gauges measurements, the axial strain calculated by equation (15-a) and numerical results. Figure 11 shows the strain of the point at the same location of channel 7 and fig. 12 show the measured values by strain gauges. Table 2 shows the calculated values of axial strain of point at the same location as channel 22 and in fig. 13, these values were plotted at the measured one.

Table 2. Axial Strain of Channel 22.

\begin{tabular}{|c|c|c|c|c|c|c|c|c|}
\hline $\mathrm{P}$ (bar) & 2 & 4 & 6 & 8 & 10 & 12 & 14 & 16 \\
\hline$\varepsilon_{\mathrm{x}}\left(10^{-6}\right)$ & 11.395 & 22.789 & 34.184 & 45.579 & 56.974 & 68.369 & 79.76 & 91.158 \\
\hline
\end{tabular}

\section{REFERENCES}

[1] Timoshenko SP, Gere JM. Theory of elastic stability. New York: McGraw-Hill, 1961.

[2] Xue J., Hoo Fatt M.S.Buckling of anon-uniform, long cylindrical shell subjected to external hydrostatic pressure. Elsevier Applied Science Publishers, Engineering Structure 24, 2002.

[3] John R. MacKay. Experimental investigation of the strength of damaged pressure hulls - Phase 2. Defense Research and Development Canada Atlantic 2007.

[4] Gerald Wempner, Demosthenes Talaslidis. Mechanics of solids and shells Theories and Approximations. CRC Press 2003.

[5] Timoshenko SP, Woinowsky S. Theory of plates and shells. New York: McGrawHill, Second Edition 1976.

[6] Eduard V, Theodor K. Thin plates and shells, theory, analysis and application. New York: Marcel Dekker 2001.

[7] Chair of Elasticity. An Approach to the analysis of thin shell. Military Tech. College, Cairo 1967.

[8] Feodosyev V. Strength of Material. Moscow 1986.

[9] Control Software PCD-30A :Instruction Manual. Electronic Instruments co., KYOWA product.

[10] HKS. ABAQUS user's manual: theoretical manual, ABAQUS post manual and example problem, Version 6.5. Hibbit, Karlsson and Sorensen, Inc; 2001. 


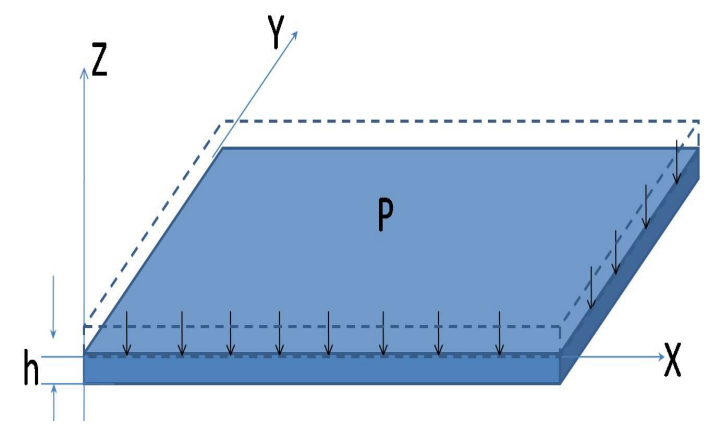

Fig. 1. Rectangular plate under uniform load.

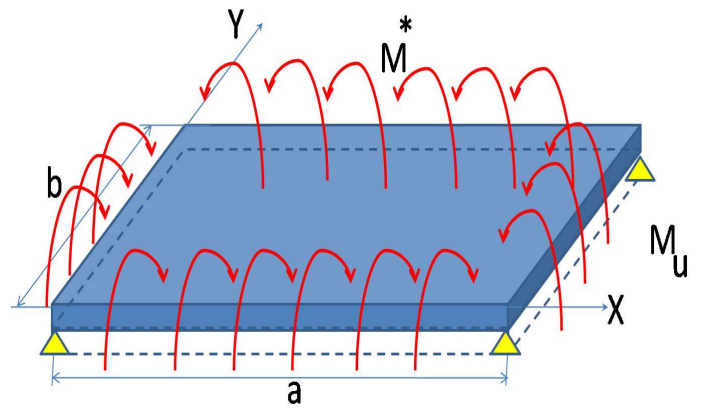

Fig. 2. Rectangular plate under boundary bending.

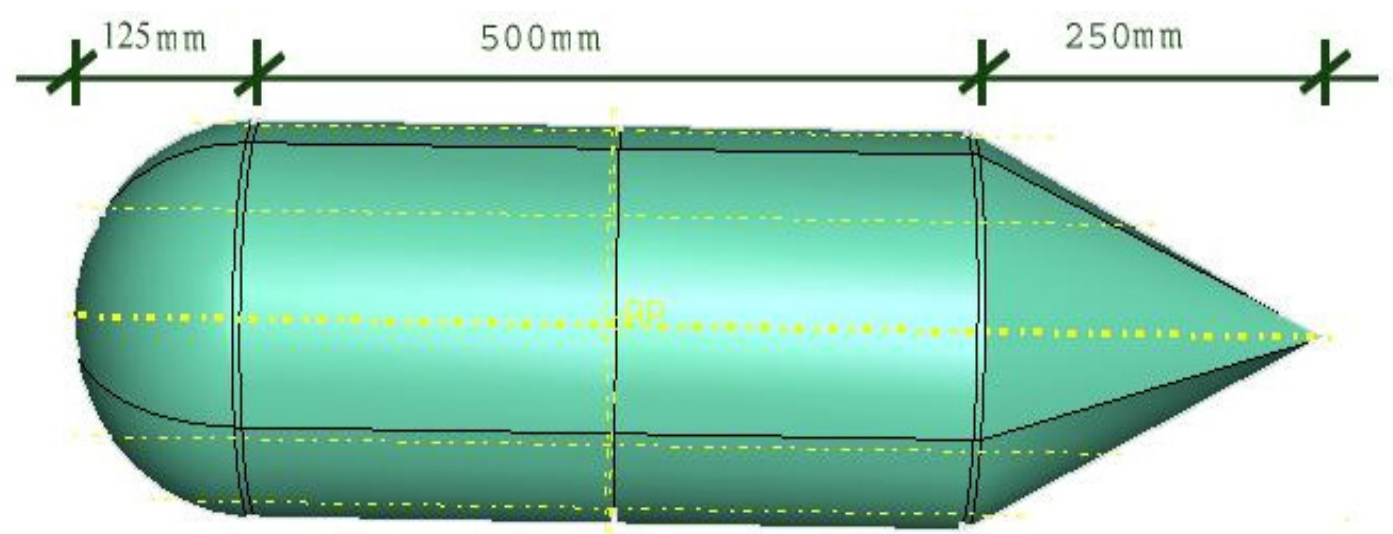

Fig. 3. Model main dimensions.

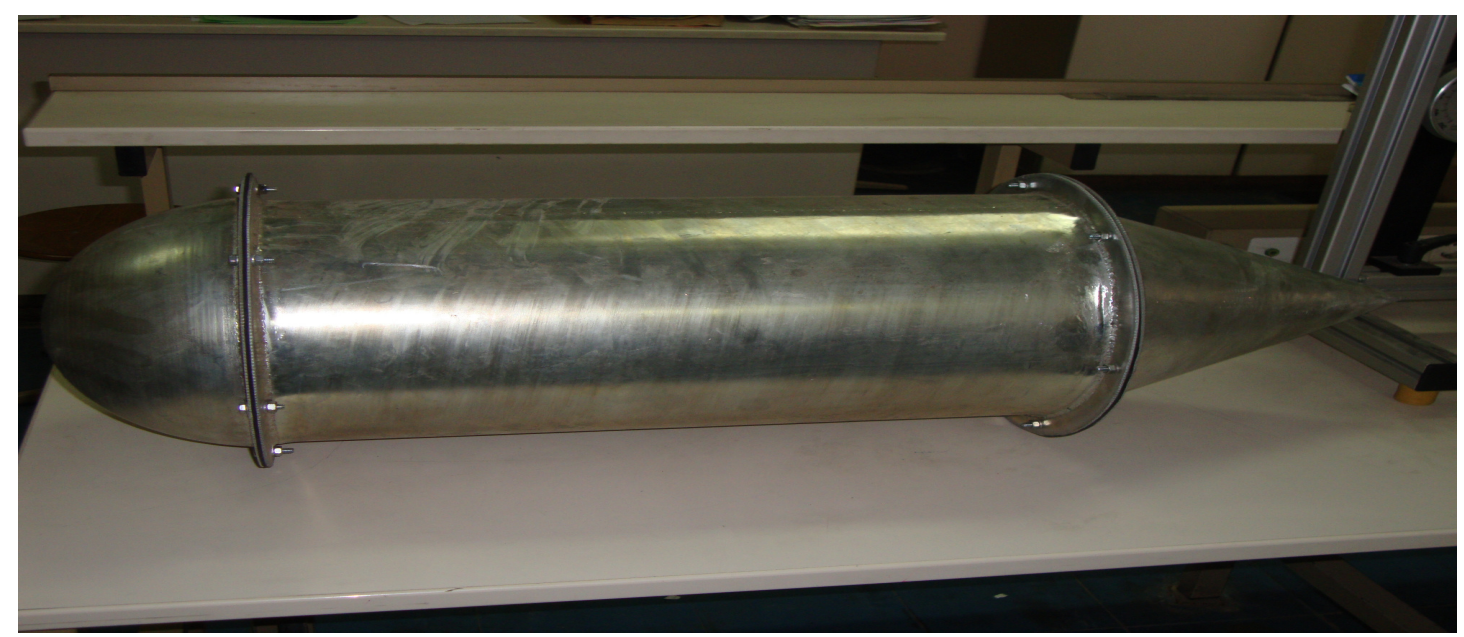

Fig. 4. The model used in experimental study. 


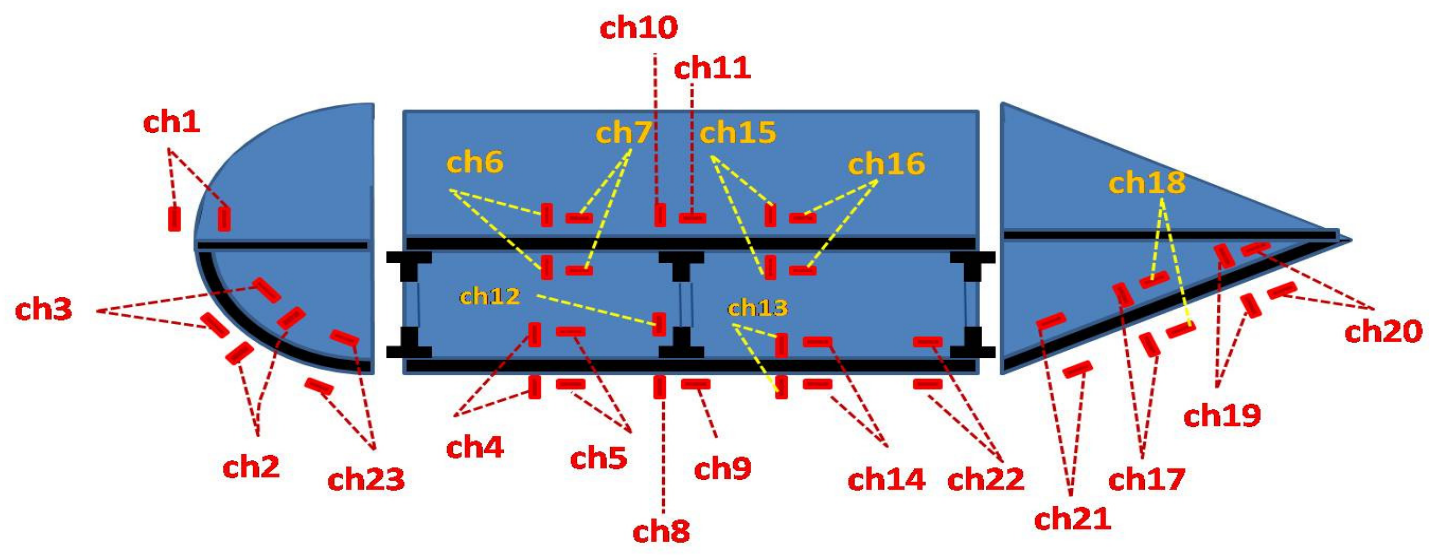

Fig. 5. Location of glued strain gauges.

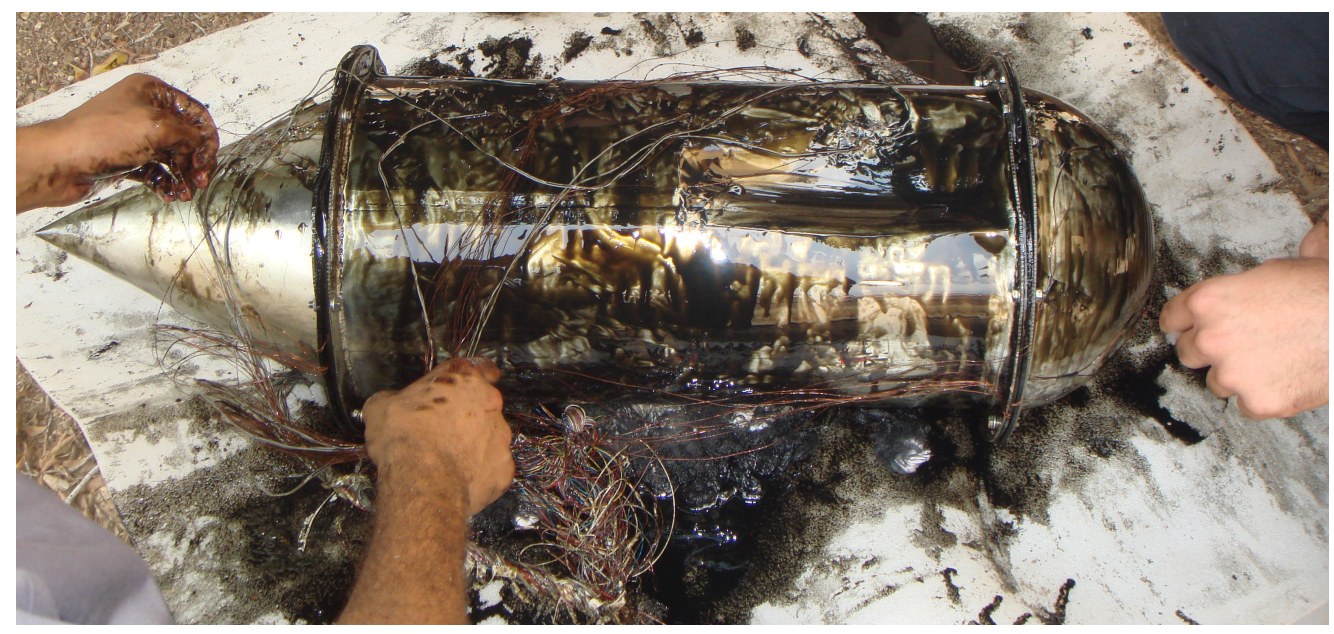

Fig. 6. The shape of the deformed model.

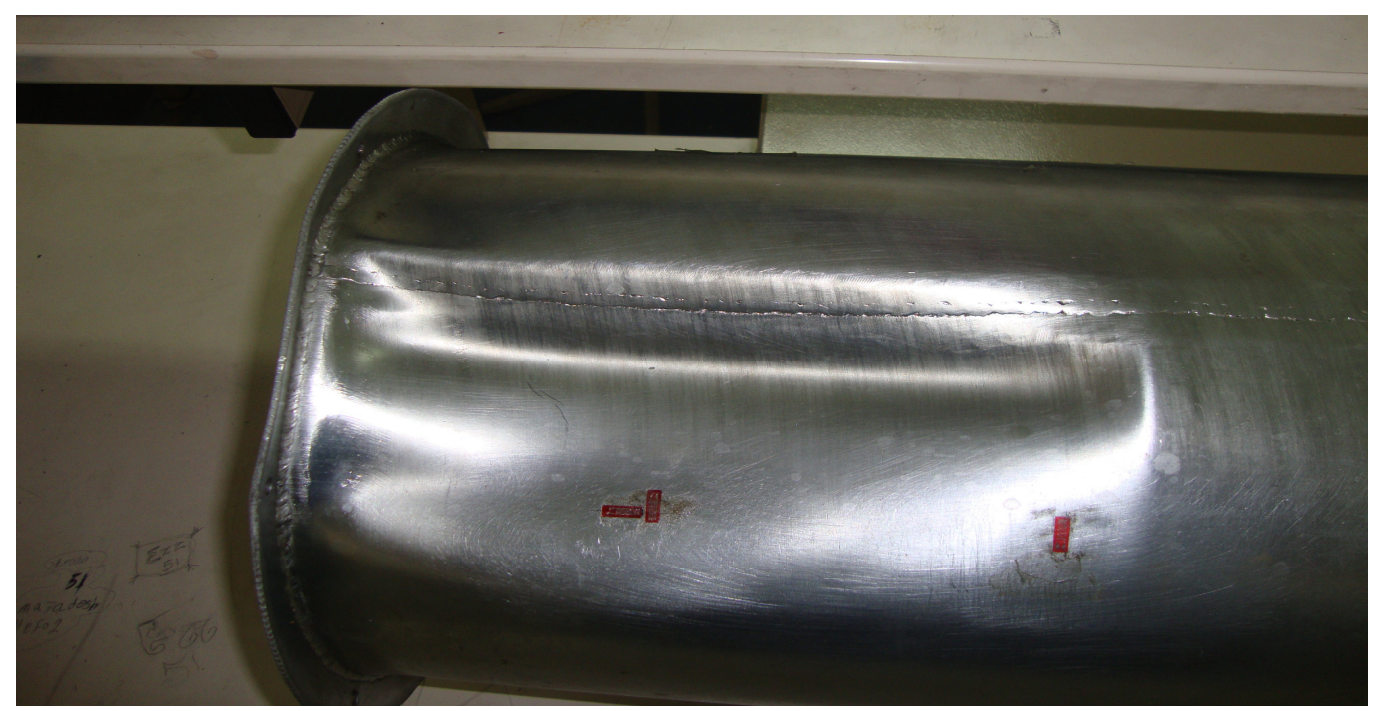

Fig. 7. The deformed part in cylinder shell. 


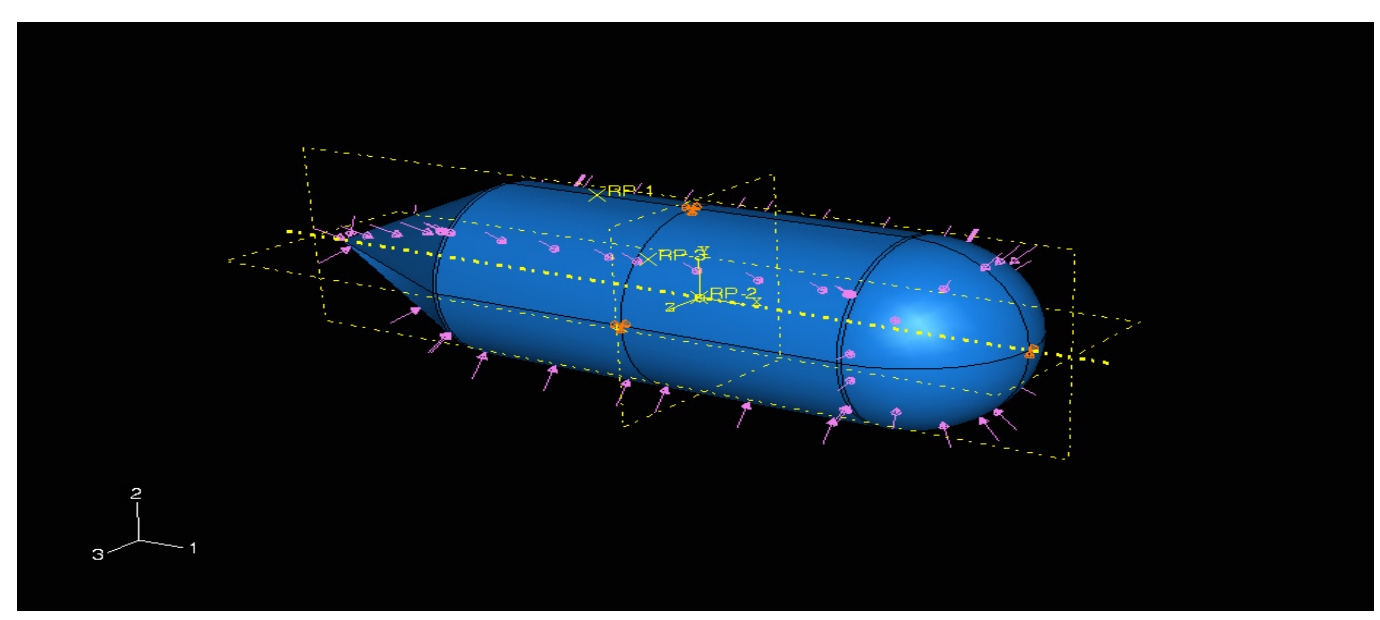

Fig. 8. Model loaded and boundary conditions.

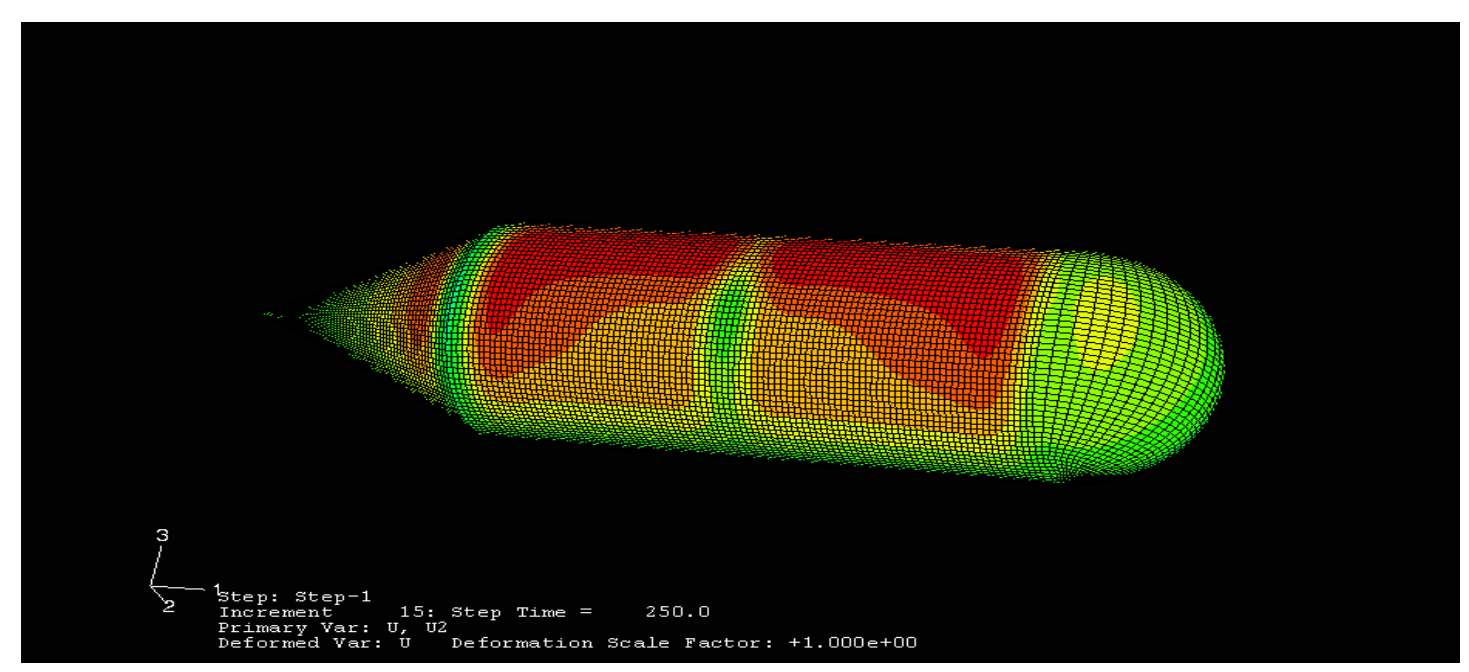

Fig. 9. Numerical results.

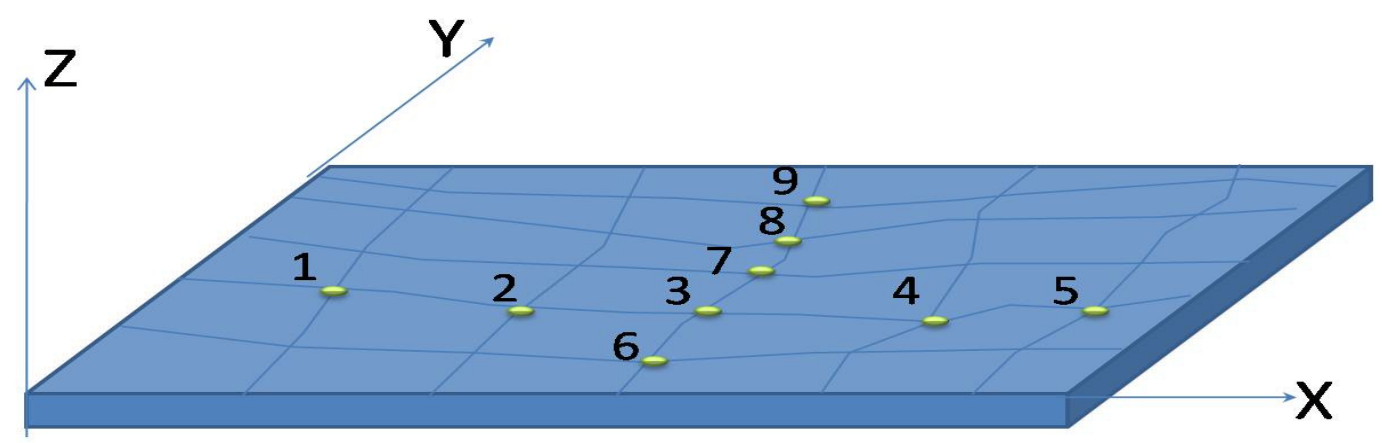

Fig. 10. The locations of points where radial deflection is measured. 


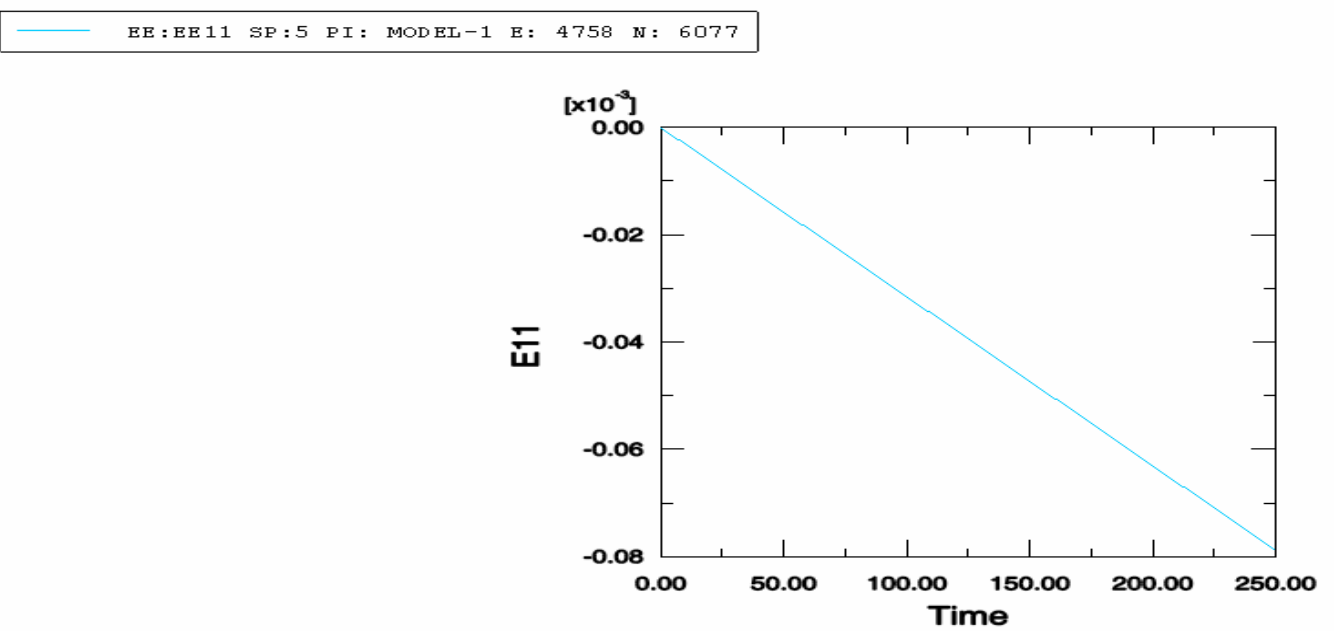

Fig. 11. Numerical result of axial strain of point at channel 7 .

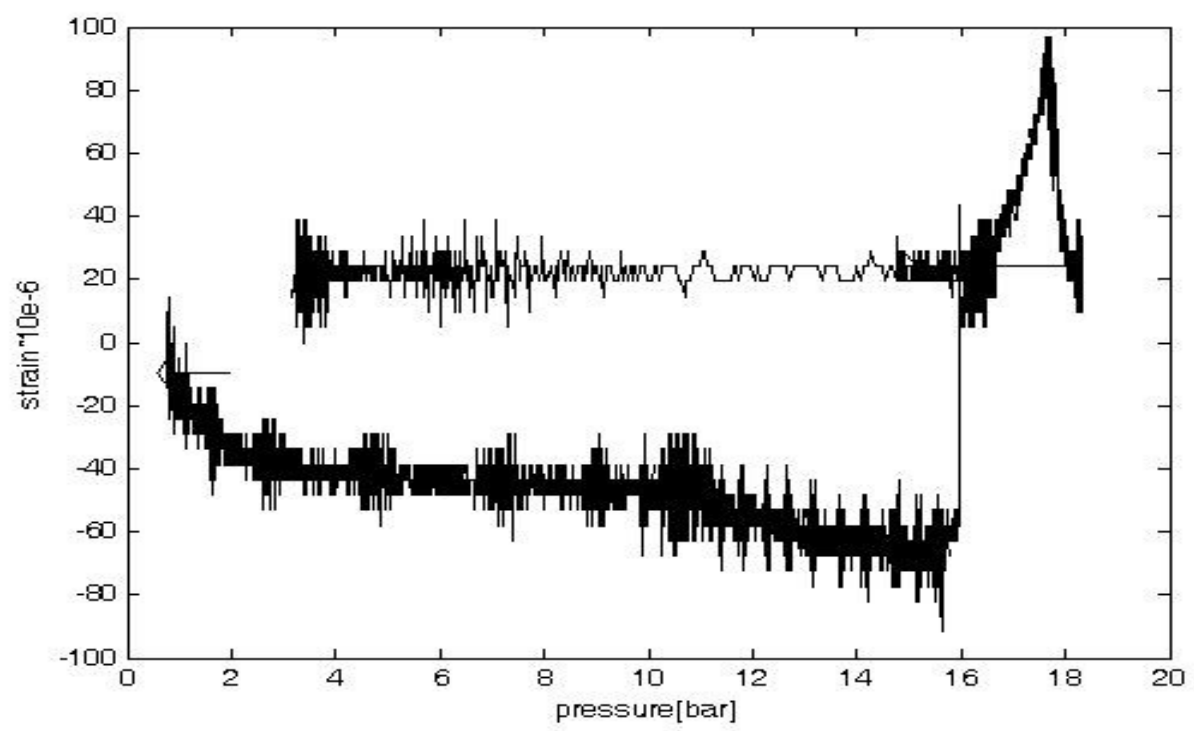

Fig. 12. Measured axial strain of point at channel 7.

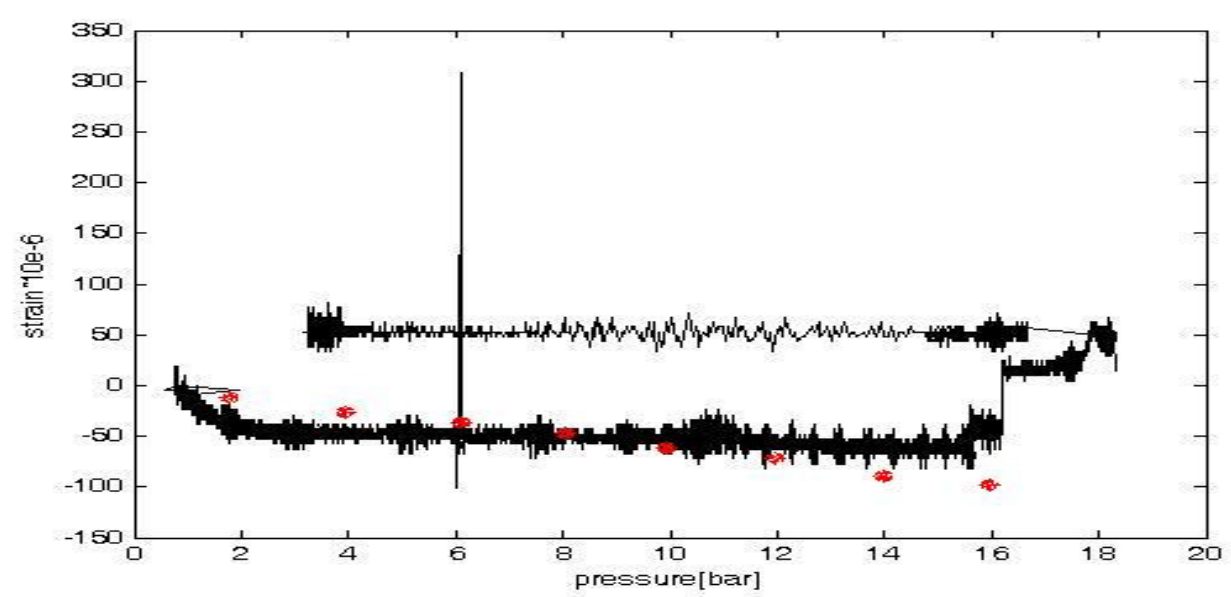

Fig. 13. Comparison between strain measured and calculated for point at channel 22 . 